\title{
Efficacy and safety outcomes of ticagrelor compared with clopidogrel in elderly Chinese patients with acute coronary syndrome
}

This article was published in the following Dove Press journal:

Therapeutics and Clinical Risk Management

14 July 2016

Number of times this article has been viewed

\section{Huidong Wang' \\ Xin Wang ${ }^{2}$}

'Geriatric Department, The Fourth Clinical College of Harbin Medical University, Harbin, ${ }^{2}$ Geriatric Department, Daqing Oilfield General Hospital, Daqing, Heilongjiang, People's Republic of China
Correspondence: Huidong Wang Geriatric Department, The Fourth Clinical College of Harbin Medical University, 37 Yiyuan Street, Nangang District, Harbin 150000 , Heilongjiang, People's Republic of China Email 2159540679@qq.com
Objective: This study was designed to investigate the efficacy and safety outcomes of ticagrelor in comparison with clopidogrel on a background of aspirin in elderly Chinese patients with acute coronary syndrome (ACS).

Patients and methods: A double-blinded, randomized controlled study was conducted, and 200 patients older than 65 years with the diagnosis of ACS were assigned 1:1 to take ticagrelor or clopidogrel. The course of treatment was required to continue for 12 months.

Results: The median age of the whole cohort was 79 years (range: 65-93 years), and females accounted for $32.5 \%$ ( 65 patients). Baseline characteristics and clinical diagnosis had no significant difference between patients taking ticagrelor and clopidogrel; they were also balanced with respect to other treatments ( $P>0.05$ for all). The risk of cardiovascular death was significantly lower in patients taking ticagrelor compared with clopidogrel, as was the risk of myocardial infarction $(P<0.05$ for all); there was no difference in the risk of stroke $(P>0.05)$. Ticagrelor was more effective than clopidogrel in decreasing the primary efficacy end point (cardiovascular death, myocardial infarction, and stroke, $P<0.05)$. The all-cause mortality was not significantly different between patients taking ticagrelor and clopidogrel $(P>0.05)$. The difference in the risk of bleeding, platelet inhibition and patient outcomes major bleeding (life-threatening bleeding and others), and platelet inhibition and patient outcomes minor bleeding was not evident between patients taking ticagrelor and clopidogrel ( $P>0.05$ for all).

Conclusion: The current study in elderly Chinese patients with ACS demonstrated that ticagrelor reduced the primary efficacy end point at no expense of increased bleeding risk compared with clopidogrel, suggesting that ticagrelor is a suitable alternative for use in elderly Chinese patients with ACS.

Keywords: acute coronary syndrome, Chinese elderly, clopidogrel, ticagrelor

\section{Introduction}

Morbidity of acute coronary syndrome (ACS) keeps a rapid growth in the People's Republic of China, while aspirin and adenosine diphosphate $\mathrm{P} 2 \mathrm{Y} 12$ receptor comprise the standard dual antiplatelet therapy (DAPT) in patients with ACS. ${ }^{1}$ As a new developed P2Y12 receptor antagonist, ticagrelor is chosen to perform the optimization of DAPT due to its direct and reversible role. ${ }^{2-4}$ Because ticagrelor does not need metabolic activation and has less interindividual variation in drug action, it is a more potent antiplatelet drug in comparison with clopidogrel. In the global Phase III PLATelet inhibition and patient Outcomes (PLATO) trial, ticagrelor exceeded clopidogrel in reducing cardiovascular (CV) death. ${ }^{5}$ However, the finding is difficult to apply to specific age groups and individual national regions in the light of the 
diversity in patients enrolled in multinational trial. Age features as a strong predictor of adverse prognosis after $\mathrm{ACS},{ }^{6-8}$ and elderly patients with ACS are at increased risk of $\mathrm{CV}$ death as well as drug-related bleeding complications. ${ }^{9,10}$ In addition, difference in demographics, comorbidities, disease patterns, and genetic backgrounds of the Chinese patients with ACS leads to diverse prognostic result and bleeding risk. ${ }^{11-13}$ Hence, poor prognostic effect and excessive bleeding risk are viewed as the primary concerns for selecting antiplatelet drugs for elderly Chinese patients with ACS. ${ }^{14}$ However, it remains uncertain on the choice of clopidogrel vs ticagrelor in the therapy of elderly Chinese patients with ACS. The current study was designed to investigate the efficacy and safety outcomes of ticagrelor in comparison with clopidogrel on a background of aspirin in elderly Chinese patients with ACS.

\section{Patients and methods}

\section{Study participants}

A double-blind, randomized controlled study was conducted in Harbin, People's Republic of China. A total of 200 patients older than 65 years were recruited from August 2013 to November 2014 and randomly assigned 1:1 to take ticagrelor or clopidogrel in double-blind fashion with the least delay after admission. Based on the sample size calculation ( $\alpha=0.05, \beta=0.2), 200$ cases were enough for this study. Patients were included with the diagnosis of ACS made according to the European Society of Cardiology guideline, and excluded if they: 1) had any contraindication against the use of P2Y12 inhibitors, 2) were under DAPT, anticoagulation, and fibrinolytic therapy, 3) had active bleeding or increased bleeding risk such as malignancy, surgery, trauma, fracture, or organ biopsy, 4) had clinically significant outof-range values for platelet count or hemoglobin, and 5) had renal function failure requiring dialysis, hypertension with systolic blood pressure $>180 \mathrm{mmHg}$ or diastolic blood pressure $>110 \mathrm{mmHg}$, or cardiogenic shock with systolic blood pressure $<80 \mathrm{mmHg}$ lasting for $>30$ minutes. $^{2}$ The study protocol was approved by the Ethics Committee of Fourth Clinical College of Harbin Medical University and performed according to the Declaration of Helsinki. Each participant provided written informed consent to be included in the study.

\section{Dosing regimens}

The initial loading dose (LD) of drug was administered as soon as possible after randomization with the first maintenance dose (MD) administered at the usual time. Clopidogrel was administered at a $300 \mathrm{mg}$ LD with an MD of $75 \mathrm{mg}$ once daily. Ticagrelor was administered at a $180 \mathrm{mg}$
$\mathrm{LD}$, and then an MD of $90 \mathrm{mg}$ twice daily. All patients took aspirin at an LD of $300 \mathrm{mg}$ followed by an MD of $100 \mathrm{mg}$ once daily, unless aspirin was intolerant. The course of treatment was required to continue for 12 months.

\section{Follow-up procedures}

Follow-up visit was scheduled at 12 months after randomization or until death occurred before 12 months, with a safety follow-up visit 1 month after the end of treatment. No patient dropped out during the study period. The primary efficacy end point was the composite of myocardial infarction (MI), stroke, or CV death. The secondary efficacy variables were MI, stroke, CV death, all-cause death, recurrent cardiac ischemia, transient ischemic attack, and other arterial thrombotic events. The safety variables were bleeding (any bleeding episode), PLATO major bleeding (life-threatening and others), and PLATO minor bleeding (requiring medical intervention). All variables were determined as defined in PLATO trial. $5,15,16$

\section{Statistical analyses}

Continuous variable was described as mean (with standard deviation) or median (with interquartile range), and categorical variable as number. Continuous variable was compared with Student's $t$-test or Mann-Whitney $U$-test, and categorical variable with chi-square test. End event was analyzed with Cox regression, and event risk in patients taking ticagrelor relative to patients taking clopidogrel was described as hazard ratio with $95 \%$ confidence interval. Survival curves were generated by means of Kaplan-Meier estimates. All analyses were conducted using SPSS 17.0 (SPSS Inc., Chicago, IL, USA) and with two-sided significance level of 0.05 .

\section{Results}

The median age of the whole cohort was 79 years (range: 65-93 years), and females accounted for 32.5\% (65 patients). As shown in Table 1, baseline characteristics and clinical diagnosis had no significant difference between patients taking ticagrelor and clopidogrel; they were also balanced with respect to other treatments ( $P>0.05$ for all). The risk of $\mathrm{CV}$ death was significantly lower in patients taking ticagrelor compared with clopidogrel, as was the risk of MI $(P<0.05$ for all; Table 2); there was no difference in the risk of stroke $(P>0.05)$. Ticagrelor was more effective than clopidogrel in decreasing the primary efficacy end point (CV death, MI, and stroke, $P<0.05$ ). The all-cause mortality was not significantly different between patients taking ticagrelor and clopidogrel $(P>0.05)$. The risk in the composite of all-cause death, MI, and stroke and the composite of CV death, MI, stroke, recurrent cardiac ischemia, transient ischemic attack, 
Table I Baseline characteristics, diagnosis, and management

\begin{tabular}{|c|c|c|c|}
\hline Variables & $\begin{array}{l}\text { Clopidogrel } \\
(n=100)\end{array}$ & $\begin{array}{l}\text { Ticagrelor } \\
(n=100)\end{array}$ & $P$-value \\
\hline \multicolumn{4}{|l|}{ Baseline characteristics, n (\%) } \\
\hline $\begin{array}{l}\text { Age, median (interquartile } \\
\text { range) }\end{array}$ & $80(74-86)$ & $79(76-85)$ & 0.833 \\
\hline Female & $34(34 \%)$ & $31(31 \%)$ & 0.651 \\
\hline Smoker & $4 \mid(4 \mid \%)$ & 37 (37\%) & 0.562 \\
\hline DM & $39(39 \%)$ & $42(42 \%)$ & 0.666 \\
\hline Dyslipidemia & 79 (79\%) & 84 (84\%) & 0.363 \\
\hline Hypertension & 82 (82\%) & 79 (79\%) & 0.592 \\
\hline Angina pectoris & $36(36 \%)$ & 40 (40\%) & 0.560 \\
\hline Prior MI & $15(15 \%)$ & $17(17 \%)$ & 0.700 \\
\hline Prior $\mathrm{PCl}$ & $6(65 \%)$ & $3(3 \%)$ & 0.495 \\
\hline Prior CABG & $0(0)$ & $0(0)$ & \\
\hline $\mathrm{CHF}$ & $9(9 \%)$ & $13(13 \%)$ & 0.366 \\
\hline TIA & $14(14 \%)$ & $16(16 \%)$ & 0.692 \\
\hline Nonhemorrhagic stroke & $10(10 \%)$ & II (II\%) & 0.818 \\
\hline PAD & 7 (7\%) & $5(5 \%)$ & 0.552 \\
\hline CKD & 13 (I3\%) & $12(12 \%)$ & 0.831 \\
\hline Diagnosis, n (\%) & & & 0.755 \\
\hline STEMI & 32 (32\%) & 37 (37\%) & \\
\hline NSTEMI & 47 (47\%) & 44 (44\%) & \\
\hline UA & 21 (2I\%) & $19(19 \%)$ & \\
\hline \multicolumn{4}{|l|}{ Risk, n (\%) } \\
\hline TIMI risk score $\geq 3$ & 95 (95\%) & $96(96 \%)$ & 0.733 \\
\hline \multicolumn{4}{|l|}{ Management, n (\%) } \\
\hline Aspirin & $100(100 \%)$ & $100(100 \%)$ & \\
\hline Nitrates & 89 (89\%) & 90 (90\%) & 0.818 \\
\hline ACEI/ARB & 67 (67\%) & $61(61 \%)$ & 0.377 \\
\hline$\beta$-Blocker & 74 (74\%) & $69(69 \%)$ & 0.434 \\
\hline Calcium channel blocker & $63(63 \%)$ & $69(69 \%)$ & 0.370 \\
\hline Statin & 79 (79\%) & $83(83 \%)$ & 0.471 \\
\hline Proton pump inhibitor & $33(33 \%)$ & 31 (3I\%) & 0.762 \\
\hline Coronary angiography & 83 (83\%) & 86 (86\%) & 0.558 \\
\hline $\mathrm{PCl}$ during study & 7I (7I\%) & 75 (75\%) & 0.524 \\
\hline CABG during study & $0(0)$ & $0(0)$ & \\
\hline
\end{tabular}

Abbreviations: $A C E l$, angiotensin-converting enzyme inhibitor; $A R B$, angiotensin receptor blocker; $\mathrm{CABG}$, coronary artery bypass graft; $\mathrm{CHF}$, congestive heart failure; CKD, chronic kidney disease; DM, diabetes mellitus; MI, myocardial infarction; NSTEMI, non-ST-segment elevation Ml; PAD, peripheral arterial disease; PCI, percutaneous coronary intervention; STEMI, ST-segment elevation MI; TIA, transient ischemic attack; UA, unstable angina; TIMI, thrombolysis in myocardial infarction. and other arterial thrombotic events was similar in patients taking ticagrelor and clopidogrel $(P>0.05$ for all). The difference in the risk of bleeding, PLATO major bleeding (life-threatening bleeding and others), and PLATO minor bleeding was not evident between patients taking ticagrelor and clopidogrel ( $P>0.05$ for all). Kaplan-Meier estimates of the composite of $\mathrm{CV}$ death/MI/stroke and bleeding for all the patients using clopidogrel or ticagrelor are shown in Figures 1 and 2.

\section{Discussion}

The current study was the first study comparing the efficacy and safety between clopidogrel and ticagrelor in elderly Chinese patients, and demonstrated that ticagrelor had the superior efficacy and similar safety relative to clopidogrel regardless of age and race. Results from the current study confirmed that patients taking ticagrelor were at lower risk of MI and CV death without more common bleeding compared with clopidogrel. Lower risk of the primary efficacy end point was also noted in patients taking ticagrelor. However, there was no differential treatment effect for all-cause mortality and other efficacy end points between ticagrelor and clopidogrel.

With the extension of lifetime and the expansion of elderly in the People's Republic of China, the Chinese elderly will account for an increasing proportion of patients with ACS in the future. ${ }^{1,17,18}$ An old age is known to be a strong predictor of thromboembolic and bleeding events as well as corresponding elevation in death risk in patients with ACS. ${ }^{6-10,19}$ Moreover, clinical prognosis of elderly with ACS is often further complicated by more common comorbidity. ${ }^{20,21}$ DAPT is crucial to prevent adverse events in patients with ACS, and ticagrelor is likely to be more

Table 2 Efficacy and safety end points

\begin{tabular}{|c|c|c|c|c|}
\hline End points & Clopidogrel $(n=100)$ & Ticagrelor $(n=100)$ & HR (95\% Cl) & $P$-value \\
\hline \multicolumn{5}{|l|}{ Efficacy end points, $n$ (\%) } \\
\hline Composite of $\mathrm{CV}$ death/MI/stroke & $22(22 \%)$ & II (II\%) & $0.473(0.230-0.976)$ & 0.043 \\
\hline Composite of all-cause mortality/MI/stroke & $22(22 \%)$ & $13(13 \%)$ & $0.558(0.28 I-1.108)$ & 0.095 \\
\hline Composite of CV death MI/stroke/RI/TIA/other ATEs & $26(26 \%)$ & $19(19 \%)$ & $0.688(0.38 \mathrm{I}-1.243)$ & 0.216 \\
\hline All-cause death & $16(16 \%)$ & $9(9 \%)$ & $0.534(0.236-1.209)$ & 0.133 \\
\hline CV death & $15(15 \%)$ & $6(6 \%)$ & $0.381(0.148-0.982)$ & 0.046 \\
\hline MI & $15(15 \%)$ & $6(6 \%)$ & $0.380(0.148-0.981)$ & 0.045 \\
\hline Stroke & $3(3 \%)$ & $2(2 \%)$ & $0.623(0.104-3.732)$ & 0.605 \\
\hline \multicolumn{5}{|l|}{ Safety end points, n (\%) } \\
\hline Bleeding & 14 (14\%) & $21(21 \%)$ & $1.410(0.717-2.774)$ & 0.319 \\
\hline PLATO major bleeding & $6(6 \%)$ & $8(8 \%)$ & $1.250(0.434-3.604)$ & 0.679 \\
\hline Life-threatening bleeding & $3(3 \%)$ & $4(4 \%)$ & $1.249(0.279-5.582)$ & $0.77 \mid$ \\
\hline Others & $3(3 \%)$ & $4(4 \%)$ & $1.252(0.280-5.593)$ & 0.769 \\
\hline PLATO minor bleeding & $8(8 \%)$ & $13(13 \%)$ & $1.531(0.634-3.694)$ & 0.343 \\
\hline
\end{tabular}

Abbreviations: ATEs, arterial thrombotic events; Cl, confidence interval; CV, cardiovascular; HR, hazard ratio; MI, myocardial infarction; PLATO, PLATelet inhibition and patient Outcomes; RI, recurrent cardiac ischemia; TIA, transient ischemic attack. 


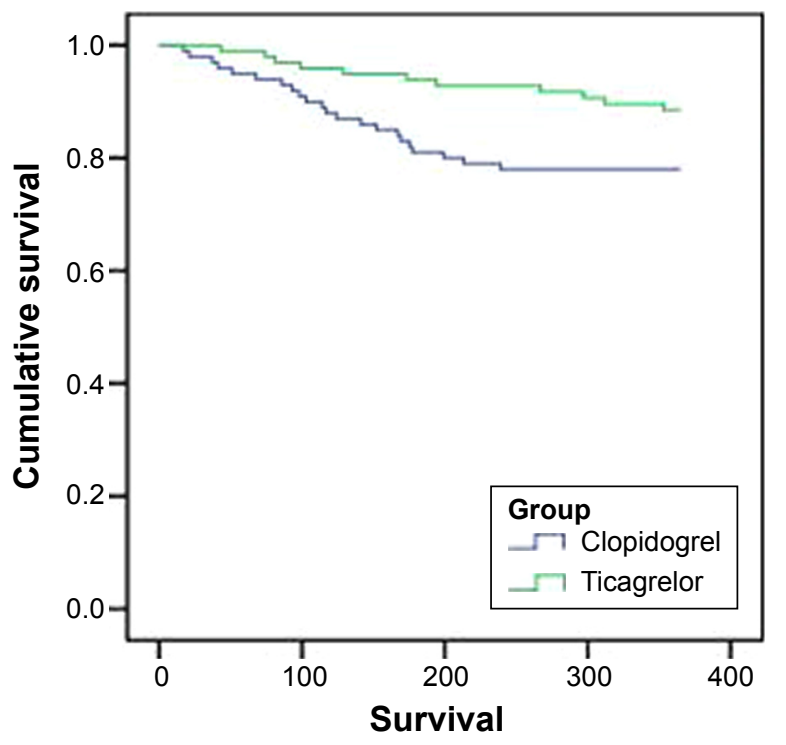

Figure I Kaplan-Meier estimate of composite of CV death/MI/stroke for all patients using clopidogrel or ticagrelor.

Abbreviations: CV, cardiovascular; MI, myocardial infarction.

suitable for DAPT. ${ }^{2-4}$ However, the evaluation of ticagrelor is insufficient in the elderly Chinese patients with ACS. The current study showed that ticagrelor had greater treatment effect on elderly Chinese patients with ACS compared with clopidogrel, and proved that ticagrelor is a more potent inhibitor of adenosine-diphosphate-induced platelet aggregation than clopidogrel in elderly Chinese patients with ACS.

Chinese patients are susceptible to have bleeding events due to the difference in demographics, comorbidities, disease patterns, and genetic backgrounds. ${ }^{11-13}$ Compared

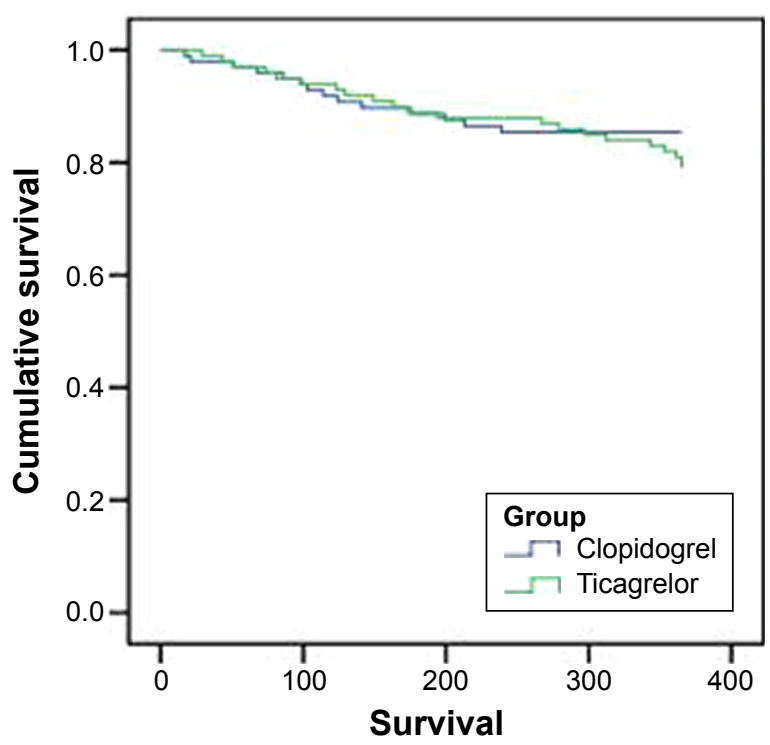

Figure 2 Kaplan-Meier estimate of bleeding for all patients using clopidogrel or ticagrelor. with clopidogrel, ticagrelor has a direct, potent, fast-acting P2Y12 inhibition in normal patients, ${ }^{22,23}$ and has been suggested to have higher levels of platelet inhibition in the Chinese patients. ${ }^{24}$ In addition to race, increased platelet inhibition of ticagrelor has been reported for elderly patients. ${ }^{24}$ However, data for difference in bleeding risk according to age and race are limited. The PLATO trial found that ticagrelor had similar overall major bleeding risk compared with clopidogrel in patients with ACS. ${ }^{5}$ The current study realized that there was no significant difference in bleeding risk between ticagrelor and clopidogrel in elderly Chinese patients.

The current study had one limitation. Although it was the first study exclusively aimed at elderly Chinese patients with ACS and it provided significant information regarding the benefit and risk of ticagrelor application in elderly Chinese patients with ACS, its sample size was relatively small, and the large-scale study will be imperative to compare the efficacy and safety outcomes of ticagrelor and clopidogrel in elderly Chinese patients with ACS.

\section{Conclusion}

The current study in elderly Chinese patients with ACS demonstrated that ticagrelor reduced the primary efficacy end point at no expense of increased bleeding risk compared with clopidogrel, suggesting that ticagrelor is a suitable alternative for use in elderly Chinese patients with ACS.

\section{Disclosure}

The authors report no conflicts of interest in this work.

\section{References}

1. Yusuf S, Zhao F, Mehta SR, et al; Clopidogrel in Unstable Angina to Prevent Recurrent Events Trial Investigators. Effects of clopidogrel in addition to aspirin in patients with acute coronary syndromes without ST-segment elevation. N Engl J Med. 2001;345(7):494-502.

2. Hamm CW, Bassand JP, Agewall S, et al; ESC Committee for Practice Guidelines. ESC Guidelines for the management of acute coronary syndromes in patients presenting without persistent ST-segment elevation: the Task Force for the management of acute coronary syndromes (ACS) in patients presenting without persistent ST-segment elevation of the European Society of Cardiology (ESC). Eur Heart J. 2011;32(23):2999-3054.

3. Jneid H, Anderson JL, Wright RS, et al; American College of Cardiology Foundation; American Heart Association Task Force on Practice Guidelines. 2012 ACCF/AHA focused update of the guideline for the management of patients with unstable angina/non-ST-elevation myocardial infarction (updating the 2007 guideline and replacing the 2011 focused update): a report of the American College of Cardiology Foundation/ American Heart Association Task Force on Practice Guidelines. Circulation. 2012;126(7):875-910.

4. Wallentin L. P2Y12 inhibitors: differences in properties and mechanisms of action and potential consequences for clinical use. Eur Heart $J$. 2009;30(16):1964-1977. 
5. Wallentin L, Becker RC, Budaj A, et al; PLATO Investigators. Ticagrelor versus clopidogrel in patients with acute coronary syndromes. $N$ Engl J Med. 2009;361(11):1045-1057.

6. Boersma E, Pieper KS, Steyerberg EW, et al. Predictors of outcome in patients with acute coronary syndromes without persistent ST-segment elevation. Results from an international trial of 9461 patients. The PURSUIT Investigators. Circulation. 2000;101(22): 2557-2567.

7. Eagle KA, Lim MJ, Dabbous OH, et al; GRACE Investigators A validated prediction model for all forms of acute coronary syndrome: estimating the risk of 6-month post-discharge death in an international registry. JAMA. 2004;291(22):2727-2733.

8. Granger CB, Goldberg RJ, Dabbous O, et al; Global Registry of Acute Coronary Events Investigators. Predictors of hospital mortality in the global registry of acute coronary events. Arch Intern Med. 2003;163(19): 2345-2353.

9. Lopes RD, Alexander KP. Antiplatelet therapy in older adults with non-ST-segment elevation acute coronary syndrome: considering risks and benefits. Am J Cardiol. 2009;104(5 Suppl):16C-21C.

10. Newby LK. Acute coronary syndromes in the elderly. J Cardiovasc Med (Hagerstown). 2011;12(3):220-222.

11. Bhatt DL, Pare G, Eikelboom JW, et al; CHARISMA Investigators The relationship between CYP2C19 polymorphisms and ischaemic and bleeding outcomes in stable outpatients: the CHARISMA genetics study. Eur Heart J. 2012;33(17):2143-2150.

12. Wang TY, Chen AY, Roe MT, et al. Comparison of baseline characteristics, treatment patterns, and in-hospital outcomes of Asian versus nonAsian white Americans with non-ST-segment elevation acute coronary syndromes from the CRUSADE quality improvement initiative. Am J Cardiol. 2007;100(3):391-396.

13. Mehta RH, Parsons L, Peterson ED; National Registry of Myocardial Infarction Investigators. Comparison of bleeding and in-hospital mortality in Asian-Americans versus Caucasian-Americans with ST-elevation myocardial infarction receiving reperfusion therapy. Am J Cardiol. 2012;109(7):925-931.

14. Levine GN, Jeong YH, Goto S, et al. Expert consensus document: world heart federation expert consensus statement on antiplatelet therapy in East Asian patients with ACS or undergoing PCI. Nat Rev Cardiol. 2014;11(10):597-606.

15. Thygesen K, Alpert JS, Jaffe AS, et al. Third universal definition of myocardial infarction. J Am Coll Cardiol. 2012;60(16):1581-1598.
16. James $\mathrm{S}, \mathrm{Akerblom} \mathrm{A,} \mathrm{Cannon} \mathrm{CP,} \mathrm{et} \mathrm{al.} \mathrm{Comparison} \mathrm{of} \mathrm{ticagrelor,} \mathrm{the}$ first reversible oral P2Y(12) receptor antagonist, with clopidogrel in patients with acute coronary syndromes: rationale, design, and baseline characteristics of the PLATelet inhibition and patient Outcomes (PLATO) trial. Am Heart J. 2009;157(4):599-605.

17. Centers for Disease Control (CDC). Trends in aging-United States and worldwide. MMWR Morb Mortal Wkly Rep. 2003;52(6):101-104.

18. Jokhadar M, Wenger NK. Review of the treatment of acute coronary syndrome in elderly patients. Clin Interv Aging. 2009;4():435-444.

19. Avezum A, Makdisse M, Spencer F, et al. Impact of age on management and outcome of acute coronary syndrome: observations from the Global Registry of Acute Coronary Events (GRACE). Am Heart J. 2005;149(1): 67-73.

20. Alexander KP, Newby LK, Cannon CP, et al; American Heart Association Council on Clinical Cardiology; Society of Geriatric Cardiology. Acute coronary care in the elderly, part I: non-ST-segment-elevation acute coronary syndromes: a scientific statement for healthcare professionals from the American Heart Association Council on Clinical Cardiology: in collaboration with the Society of Geriatric Cardiology. Circulation. 2007;115(19):2549-2569.

21. Alexander KP, Newby LK, Armstrong PW, et al; American Heart Association Council on Clinical Cardiology; Society of Geriatric Cardiology. Acute coronary care in the elderly, part II: ST-segmentelevation myocardial infarction: a scientific statement for healthcare professionals from the American Heart Association Council on Clinical Cardiology: in collaboration with the Society of Geriatric Cardiology. Circulation. 2007;115(19):2570-2589.

22. Gurbel PA, Bliden KP, Butler K, et al. Response to ticagrelor in clopidogrel nonresponders and responders and effect of switching therapies: the RESPOND study. Circulation. 2010;121(10):1188-1199.

23. Storey RF, Angiolillo DJ, Patil SB, et al. Inhibitory effects of ticagrelor compared with clopidogrel on platelet function in patients with acute coronary syndromes: the PLATO (PLATelet inhibition and patient outcomes) PLATELET substudy. J Am Coll Cardiol. 2010;56(18):1456-1462.

24. Li H, Butler K, Yang L, Yang Z, Teng R. Pharmacokinetics and tolerability of single and multiple doses of ticagrelor in healthy Chinese subjects: an open-label, sequential, two-cohort, single-centre study. Clin Drug Investig. 2012;32(2):87-97.
Therapeutics and Clinical Risk Management

\section{Publish your work in this journal}

Therapeutics and Clinical Risk Management is an international, peerreviewed journal of clinical therapeutics and risk management, focusing on concise rapid reporting of clinical studies in all therapeutic areas outcomes, safety, and programs for the effective, safe, and sustained use of medicines. This journal is indexed on PubMed Central, CAS,

\section{Dovepress}

EMBase, Scopus and the Elsevier Bibliographic databases. The manuscript management system is completely online and includes a very quick and fair peer-review system, which is all easy to use. Visit http://www.dovepress.com/testimonials.php to read real quotes from published authors. 